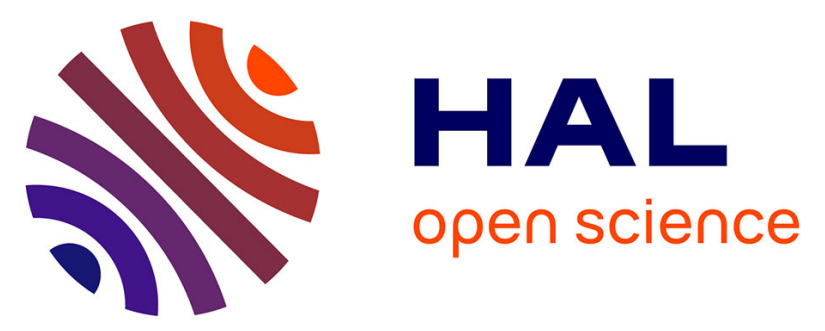

\title{
Foundation of CS-DC e-laboratory: Open Systems Exploration for Ecosystems Leveraging
}

Masatoshi Funabashi, Peter Hanappe, Takashi Isozaki, Annemarie Maes, Takahiro Sasaki, Luc Steels, Kaoru Yoshida

\section{- To cite this version:}

Masatoshi Funabashi, Peter Hanappe, Takashi Isozaki, Annemarie Maes, Takahiro Sasaki, et al.. Foundation of CS-DC e-laboratory: Open Systems Exploration for Ecosystems Leveraging. CS-DC'15 World e-conference, Sep 2015, Tempe, United States. hal-01291104

\section{HAL Id: hal-01291104 \\ https://hal.science/hal-01291104}

Submitted on 20 Mar 2016

HAL is a multi-disciplinary open access archive for the deposit and dissemination of scientific research documents, whether they are published or not. The documents may come from teaching and research institutions in France or abroad, or from public or private research centers.
L'archive ouverte pluridisciplinaire HAL, est destinée au dépôt et à la diffusion de documents scientifiques de niveau recherche, publiés ou non, émanant des établissements d'enseignement et de recherche français ou étrangers, des laboratoires publics ou privés. 


\title{
Foundation of CS-DC e-laboratory: Open Systems Exploration for Ecosystems Leveraging
}

Masatoshi Funabashi ${ }^{1}$, Peter Hanappe ${ }^{2}$, Takashi Isozaki ${ }^{1}$, AnneMarie Maes $^{34}$, Takahiro Sasaki ${ }^{1}$, Luc Steels ${ }^{2}$, and Kaoru Yoshida ${ }^{1}$

1 Sony Computer Science Laboratories, Inc. 3-14-13, Higahi-Gotanda, Shinagawa-Ku, Tokyo, Japan http://www.sonycsl.co.jp

\{masa_funabashi, isozaki, sasaki, kaoru\}@csl.sony.co.jp

2 Sony Computer Science Laboratory Paris 6 rue Amyot, 75005 Paris, France https://www.csl.sony.fr hanappe@csl.sony.fr 3 OKNO

Koolmijnenkaai 30, 1080 Brussels, Belgium http://okno.be annemie@okno.be

4 So-oN

Vlaamse Steenweg 66, 1000 Brussels, Belgium http://annemariemaes.net

\begin{abstract}
We established a Complex Systems Digital Campus(CS-DC) e-laboratory "Open Systems Exploration for Ecosystems Leveraging" in view of redesigning sustainable social-ecological systems related to food production ranging over food, health, community, economy, and environment. 6 projects have begun to collaborate in e-laboratory, namely Synecoculture, P2P Food Lab, Open Systems Data Analytics, The Bee Laboratory, Open Systems Simulation and One-Health Food Lab. As a transversal methodology we apply open systems science to deepen scientific understanding and for a continuous amelioration of the management. The projects involve scientists, engineers, artists, citizens and are open to collaboration inside and outside of the e-laboratory. This article summarizes foundational principles of these projects and reports initial steps in operation.
\end{abstract}

Keywords: Food production, agriculture, health, community, ecology, environmental problems, open systems, analytics, simulation, art, citizen science

All authors contributed equally to this article. The authors names are listed in an alphabetical order. 


\section{Introduction}

\subsection{Environmental Problems of Agriculture}

Humans have engaged in agriculture for over 10,000 years since the dawn of history, but that history has been inevitably based on the trade-off between agricultural production and environmental degradation [1][2]. Modern agriculture is still situated along the same line, further loading the environment to realize physiological optimum in large-scale monoculture. The excess practice of conventional agriculture is now considered as a major factor of environmental degradation in both terrestrial and marine ecosystems, that threatens the sustainability of our society by triggering irreversible global state shift of the environment [3]. Several International organizations provide scientific reports on the environmental degradation caused by intensive practice of conventional agriculture and associated market structure [4] [5] [6] [7] [8] [9] [10]. They commonly propose alternative models should take priority on small-scale local farming, environment-constructive method of cultivation, fair distribution and equitable trade.

\subsection{Sensing Technologies}

Recent development of sensing technology has drastically changed the precision and scope of measurement from molecular to ecosystem levels. In the level of ecosystems, remote sensing technologies are extensively applied to the measurement in large-scale agriculture and assessment of ecological state. The application has a wide range such as international assessment of climate change [11], estimation of river inundation [12], weed control [13], prediction of drought [14], resource management [15], agroecosystem modeling [16], forestry planning [17][18], estimation of crop biomass [19], and so on. The research trend is focused mainly on 2 areas, conventional agriculture systems and global observation of ecosystems: Sensing of agricultural ecosystems aims to gain specific information necessary for the prediction and control. While sensing of global ecosystems tries to capture global indicators associated with climate change in large scale.

There is however little application on the crossing area, especially on smallscale sustainable agriculture where biodiversity and cultural productivity are firmly related [20][21]. Prediction model based on remote sensing data do not sufficiently incorporate biodiversity in its models. Small scale farming between natural ecosystems and human disruption realizes rich ecosystems, which is similar to the biodiversity hotspot known as ecotone [22]. The importance of conservation effort of hotspots is due to its instability, which is considered to attribute to the chaotic behavior inherent in ecosystem dynamics [23][24]. Such complexity requires methodologies of complex systems science besides the global measurement by remote sensing. We need to develop a framework to connect between diverse sensing methods and each ecosystem agent, which would provide rich indicators on the dynamics of biodiversity. 


\subsection{Biodiversity Database}

Biodiversity is a key concept to assess the environment, evaluate the ecosystems services and measure the effect of human disruption. Biodiversity comprises plural indicators describing the degree of variation, ranging over diversity within species, between species and of ecosystems from all sources [25]. Sensing of biodiversity in small scale still demands manual labour and classification of species by human. Important conservation issues based on the environmental assessment always require such precise information. Biodiversity and taxonomy database follows international initiative in view to describe the whole species existing on the earth [26][27][28][29][30][31][32][33]. These databases are complementary to remote sensing measurement, and both should be assembled to obtain a multiscale interpretation of an ecosystem state. To establish a fine-grained measurement compatible to the concept of biodiversity, we have to proceed from several paths, such as refinement of sensing methods, models of biodiversity, and human observation, through an integrated development of technology, modeling and practice.

Biodiversity is also finely related with local diet and health in traditional food, which is compatible to the growing needs in sustainable agriculture [34]. Foods are major factors of health amidst recent life style changes [35][36]. It is important to explore the relation between environment, food, nutrition, and human health with the use of nutritional and biodiversity database.

\subsection{Citizen Science and Virtual Platform}

Development of information technologies and invention of mobile terminal such as smartphone has introduced a novel realm of interaction in citizen science. Diversity record related to geographical information has become possible to organize participation of individuals on site. The cloud sourcing of data collection is expected to be more accessible to local activities and essential to consider management on the diversity [37]. Integrated expression of environmental data on virtual globe software such as Google Earth is rapidly gaining its popularity. Participatory use of such platform can gather expert knowledge as well as laypeople observation, bridge the gap between professionals and amateurs, and is compelling to raise public awareness on the management including ethical discussion [38]. Virtual platform of environmental information with geographical expression can be a prominent platform to integrate sensing data, biodiversity database, and citizen observation.

\subsection{Challenge of the e-laboratory: Towards Citizen Prototype of Sustainable Agriculture -Exploring Ecosystem Agents as a Symbiotic Interface between Human and Nature-}

Our e-laboratory gathers scientists, engineers, and artists to tackle the sustainability issues in food production and ecosystems management, ranging from 
urban gardening to agricultural production, from on-the-fly exploration to integrative simulation, from human to environmental health, from data analytics to artistic expression[39]. Sensing technologies, databases, analytics, and citizen science will be combined in order to realize the leveraging of ecosystem services via human activity. The initial projects comprise 6 projects, namely Synecoculture(sec.2), P2P Food Lab(sec.4), Open Systems Data Analytics(sec.3), The Bee Laboratory(sec.5), Open Systems Simulation(sec.6), and One-Health Food Lab(sec.7). Our challenge aims to yield the potentials of self-organizing nature of ecosystems with the bottom-up organization of each project. By exploring ecosystem agents as a symbiotic interface between human and nature, this challenge would consequently be led to develop diverse, parallelly distributed practices of sustainable food production and related scientific domains.

(Masatoshi Funabashi)

\section{Synecoculture}

\subsection{An Alternative: Polyculture System with Ecological Optimum}

Plants have been one of the main agents that transformed terrestrial environment through surprisingly intelligent adaptation and coevolution [40]. Ecosystems have been evolved by developing complex networks containing both competitions and symbiotic relations as a result of ecological optimum [41], which formed today's biosphere we live in. Indeed, natural ecosystems compatible to agricultural field such as grassland and forest is known to express symbiosisdominant effect on biomass production with respect to the species diversity [42][43]. Such productivity based on the ecological optimum is not yet sufficiently exploited in agricultural framework. The application of ecological optimum has been partially practiced in agriculture by perennial crops polyculture [44][45][46], no-till farming [47], natural farming [48], etc. The difficulty of cultivation method lies in the optimization of management cost and the productivity with a context of marketing. The challenge requires strong support of information technologies with open complex systems perspectives [49].

Considering the bottom-up emergence of biodiversity in ecological optimum, the measurement and control is difficult to achieve in a centralized top-down manner. We propose an alternative way, the organization of citizen science to collect and share the experience of diversified polyculture practice. By sharing the data and knowledge with the use of information technology, citizen science has a possibility to realize both diversity and flexibility of measurement and management, which may be more compatible to the dynamics of ecosystems [49].

\subsection{Methodology of Synecoculture}

As a polyculture system with ecological optimum, we introduced a novel system of agriculture based on the synthesis of ecosystems, namely "Synecoculture", 
mainly for the culture of vegetables and fruits [50]. Synecoculture is a high density mixed polyculture of edible species, that stems from the observation of natural ecotone and biodiversity hotspots. We associate plants according to their symbiotic interactions with soil, environment, and other vegetation, which augments the biodiversity of the culture beyond natural state. The fields overlap with a transition to mature secondary vegetation with human use [51]. The management of culture is based on the diversity and succession, similar to the forest renewal. We first plan the vegetation according to the environmental condition, and let the ecosystem self-organize the products with least human intervention: No tillage, no fertilizer, no chemicals, other than introduction of edible species. We harvest from the formation of ecological niche, in which thinning harvest from mixed and dense vegetation is effective for both year-round harvest and weed control. This system brings us quite diverse products all round year with extended culture seasons and thus suitable for local daily consumption.

\subsection{Experiments of Synecoculture}

Experiments of Synecoculture take place in several fields including professional farms and family gardens in Japan. Edible plant species numbers introduced In the proof of concept experiments are listed in Table 1 . The edible species diversity introduced in Synecoculture fields, nothing but on monitored $0.3 \mathrm{ha}$, exceeds the item number of the traditional Satoyama agriculture in a regional scale, and is compatible in terms of cultivar variety. Although the growth of the plants are distributed in a long-tail and do not necessary survive after competition, human introduction of plant diversity interacts with both local flora and fauna, that creates a unique augmented ecosystem in ecological optimum[49]. This implies that Synecoculture has a high potential to increase agro-biodiversity even in a small scale. Items produced were sold at a commercial farm(Ise) on site, at local restaurants, including on-line sales of 80 products all over Japan.

\begin{tabular}{c|c|c||c}
\hline Ise Farms & Todoroki Farm & Oiso Farm & GIAHS Noto \\
\hline 134(133) species & $173(157)$ species & $170(158)$ species & 173 items \\
- & 467 varieties & 426 varieties & 705 varieties \\
\cline { 2 - 3 }- & $215(196)$ species, 673 varieties & \\
\hline \multicolumn{3}{c|}{ Total $263(247)$ species }
\end{tabular}

Table 1. Edible plant species diversity introduced during Synecoculture experiment in 2010/6-2014/5. Ise, Todoroki, Oiso farms are Synecoculture farms in Mie-ken, Tokyo, and Kanagawa-ken in Japan, respectively. The total experimental surface of these farms are about $0.3 \mathrm{ha}$. Other citizen farms also exist with their own initiatives. Numbers in parentheses describe the number of species that survived more than one year after introduction or produced the seeds. For a comparison, GIAHS Noto is the UNESCOcertified globally important agricultural heritage system(GIAHS) in Noto peninsula, Japan with 186,600 ha surface covering the northern half of Ishikawa-ken, renowned by its high biodiversity conservation value[52]. 


\subsection{Exploration of Ecosystem Agents as an Interface}

The productivity in ecological optimum is constrained by environmental conditions. Basic physical parameters such as temperature and precipitation are known to be the major determinants of vegetation [53][54]. Sunlight also plays central role in photosynthesis. These parameters vary depending on local geographical condition and existing vegetation. At the same time, actual plant community varies depending on the seed bank, competition, vegetation succession, delayed action of past conditions [55], etc, within the same climate classification. The bidirectional dependencies between physical conditions and vegetation is an essential basis of ecosystems as complex systems. To treat the local diversity of plant community and make use of it in polyculture system, we need to know about the actual components and dynamics of ecosystems agents besides physical parameters of the environment.

Since ancient times, phenological events such as blossoming of flowers and certain animals' behavior were considered to be key indexes to detect the seasonal phase of ecosystem dynamics. With the development of ecological database, it is possible to link such phenological biodiversity observation with practical prediction and control of ecosystems management, including farming system with ecological optimum. With the aid of database, sensing and communication technology, we can attribute each ecosystem agent to the property of interface for the management of ecosystems. Generally an interface is an element between two systems, which intermediates between inputs and outputs for certain objective. For example, harvest of edible species is the output from ecosystems, while planting, releasing, and introducing them correspond to input. one can consider each ecosystem agent as an interface to sense and make decision of input and output on ecosystem. The functional roles of plants and animals can be used as relational indexes for ecosystem management. With the development of interactive database between biodiversity observation and ecological knowledge, we try to explore and share practical framework to make use of ecosystems agents as an interface of sustainable agriculture.

As an example, Figure 1 shows the comparison between different ecosystems with common species based on the database of Synecoculture [49]. Geographically distant ecosystems can be compared in terms of biodiversity with a time line, from which we can estimate what kind of species can be commonly introduced, and what is the conditions that makes the difference. In this example, the earlier appearance of the species in Tokyo than in Paris may indicate a correlation with meteorological data such as temperature since spring comes earlier in Tokyo, which provides a candidate of effective physical parameters. In application, the species appearance can be interpreted as the biological reaction to environmental condition in total. When the culture condition is not equivalent and impossible to control each factor in an open environment in operation, the similarity of ecosystem reactions may consequently be an effective index for the management, as is the case in farming folk wisdom. In any region of the world, we can find diverse relations between climate, animals and plants that infer ecologically consistent structure. These include actual causal structure of ecosystems, 
and also so-called pseudo-correlation in a massive data analysis, the correlation without direct causality but still applicable to the actual management of complex systems. These symbols and relations form certain universal structure in human cognition in various culture, which is pointed out to be essentially common to scientific thinking [56]. To determine the factors that support a species niche is necessary to diversify the polyculture in ecological optimum, which is a complex entanglement that depends on environmental condition, associated biodiversity, farming option, etc. The analysis is further developed in collaboration with Open Systems Data Analytics, which is described in section 3.

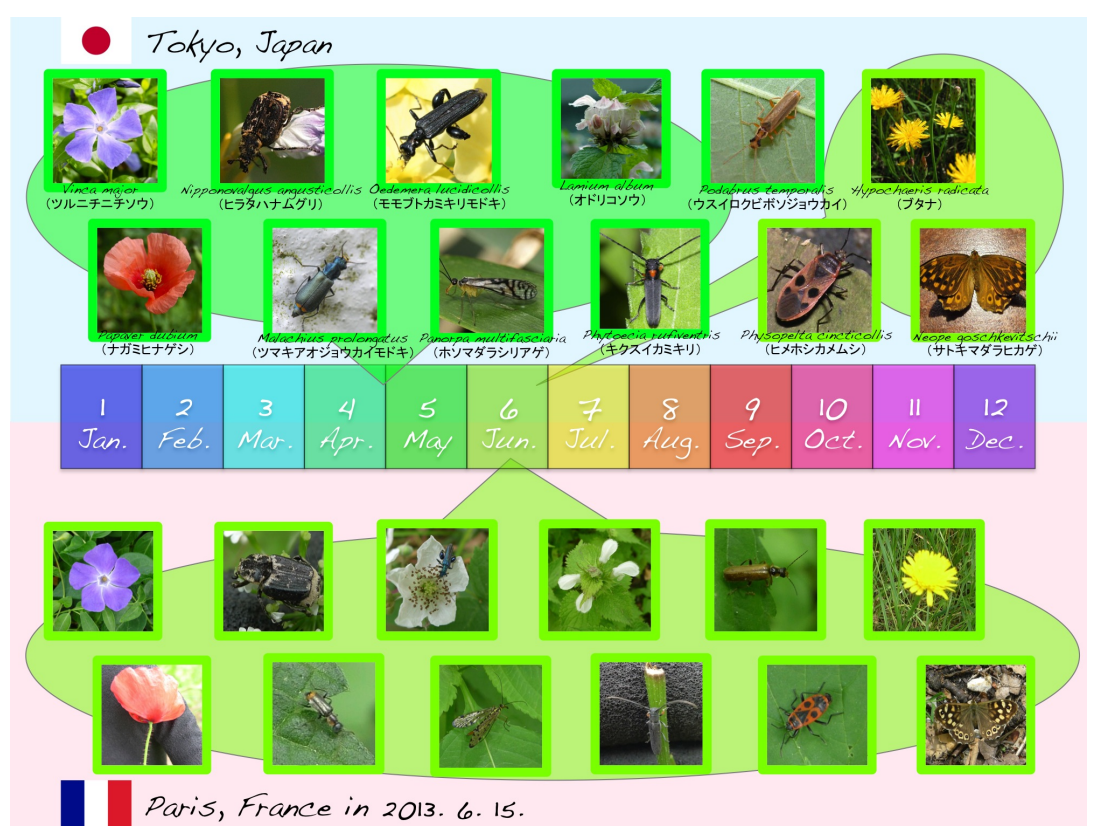

Fig. 1. Comparison of species diversity between different ecosystems on Synecoculture contents management system. Bottom: Observed species in Paris, France on 2013/6/15. Top: Corresponding species observation in Tokyo Japan, whose appearance seasons range over several months.

(Masatoshi Funabashi)

\section{Open Systems Data Analytics}

There is a growing necessity for dealing with open systems such as computer networks, healthcare, and global climatic changes. The data related to ecology and agriculture are also exponentially increasing, such as biodiversity database, monitoring data of agricultural fields, buying history of products, nutrition profile, 
geoenvironmental assessments, etc. Such "big data" is gaining greater importance on the future of human society. In Open Systems Data Analytics, we are trying to develop novel analytical tools of massive data that have many variables dependent on each other, using probabilistic graphical models and methodologies of physics [57][58].

In open systems, it is difficult to understand and control the whole systems due to their complex interactions and dependencies. Data oriented approaches are effective for understanding open systems when the subsystems are not explicitly defined. From the viewpoint of data analysis, We consider that causal relation inference from observational data is useful for understanding and managing open systems when possible practices of controlled experiments are limited during operation. Although the true cause-effect relationships is difficult to prove completely due to many unobserved variables, it is possible to make effective interventions as we augment the accuracy of the causal relationship inference in the systems [62]. A causal analysis may thus remain at the level of providing some suggestions for managing systems and repeatedly improve it with the introduction of possibly latent variables and new data .

We therefore apply Tokoro's open systems science [59] [60] with adaptation to a causal data analysis, and propose a methodology, which we call (a version of) Open Systems Data Analytics, as follows:

1. Define the problem and its domain.

2. Set variables and get their data.

3. Construct a causal model by causal inference algorithm from data.

4. If it is difficult to interpret causal relations in the model, important latent variables probably exist. Infer them and add data of the new variables to the dataset as far as possible.

5. Repeat the procedure (3)-(4) until a satisfactory result (or consensus) is obtained.

6. Do predictions, interventions, and/or construct theories.

More precisely, the definition of causal relationship is adopted from the Reichenbach's principle of causality on the sets of three (or more) variables [61]. it is based on the finding of directed Markov patterns in correlation networks for random variables by removing pseudo-correlations with statistical tests.

\subsection{Analysis of Synecoculture database}

In Synecocultur project, polyculture with ecological optimum requires a huge amount of information on biodiversity, interactions, and vegetation succession to optimize as a productive system. Such information contains huge number of parameters, generally sparse, possibly biased, open-ended, etc, because it relies on human observation. Still, it can bring useful information and intriguing insight on the management if powerful algorithmic analysis is combined with appropriate human evaluation. Open Systems Data Analytics can combine massive data analysis tools with diverse feedbacks by humans working on site, so that to 
maximize the synergy between background knowledge, computational power and human intuition. We apply the methodology to maximally augment educational effect of participants. The aim is different from conventional science that seeks for the strong reproducibility and predictability of phenomena with external observation, but rather to explore multiple choices for a better management from inside of open complex systems in operation, where internal observation is structurally inevitable.

We here demonstrate an example of the causal data analysis in Open Systems Data Analytics, the first step of the procedures (1)-(4). We analyzed biodiversity data obtained from Synecoculture farms and surrounding environment in Japan between 2011/4-2013/3. The data are the binary occurrence records of observations about plants, insects, date, and places, which defines the process (1) and (2). The analysis of the process (3) was performed using an algorithm called Combining Stage (CS) [63]. From 11911 observations that comprises 1232 variables (1150 plants and animals, 3 years, 12 months, 67 places), 1131 sets of Markov dependency were detected on 611 variables.

Figure 2 Left shows the inferred causal model with a directed graph. We evaluated the suggestion with respect to the observers' experience and classified into 3 categories:

1. Trivial such as the causality between observation places and discarded from the analysis.

2. Unknown to the experience or other literatures, therefore candidates for further observation.

3. Known to the experience or other literatures, therefore validation instance of the model.

We then evaluated the information of 2. the suggestions unknown to experience by the following information quantity $I(c)$ for each unknown suggestion with a strength of inferred causality $c$ :

$$
I(c)=-\log \left\{\frac{\#(\text { known suggestions with inferred causality } \geq c)+1}{\#(\text { known suggestions })+1}\right\},
$$

where $\#()$ represents the number of suggestions, and the additions of 1 correspond to count a chosen unknown suggestion itself. The information $I(c)$ for each unknown suggestion is defined as the information of significance (p-value in statistical tests) with respect to the known suggestion distribution as a model. It represents the amount of information that the model would gain as a reward if the unknown suggestion was revealed to represent plausible dependence by further observation. The $I(c)$ is 0 when there is no known suggestion. It expands the value range as validated known suggestions increase, which reflects the plausibility of the model with respect to the accumulation of human observation and experience.

Figure 2 Right shows the example distributions of unknown, known causality suggestions and distribution of $I(c)$ for each unknown suggestion with respect 
to the inferred causality. Unknown causality suggestions with high $I(c)$ exist, which are the preferential candidates for future observation. By incorporating these suggestions and by iterating the step 5 of Open Systems Data Analytics, it is expected to modify the observation framework by means of internal observation so that to achieve a better fit between causality analysis and observers' experience.

For further analysis, we plan to add environmental parameters such as temperature, humidity, precipitation, hours of sunlight, etc, in order to incorporate objective measures that do not depend on human subjectivity. Furthermore, since ecosystems inherently contain transient dynamics and farming options could change according to the objective of production, we expect to repeat and integrate the analysis year-by-year to investigate the degree of achievement in the steps 5 and 6 .
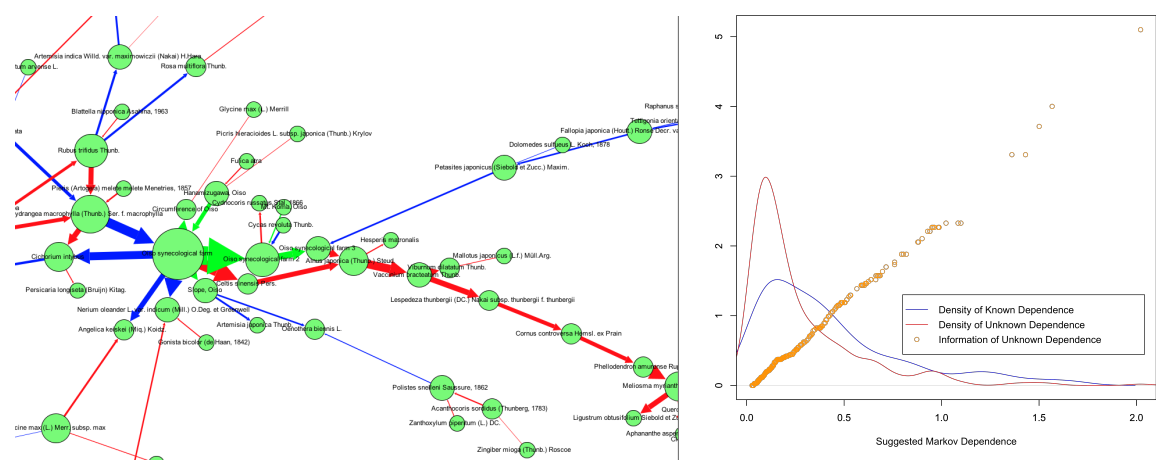

Fig. 2. Left: Graph visualisation of the causality suggestion. The circles and the edges denote variables and Markov dependencies between two variables, and the line thickness denotes strength of dependencies quantified by mutual information. For variables $A$ and $B$ in the figure, if $A \rightarrow B, A$ denotes a cause of $B$ in the sense of Markov dependence. Colours of edges indicate that the suggestion was 1. trivial(green), 2. unknown(red) and 3. known(blue) to the observer's experience. An undirected edge means that there is a Markov dependence but without significant inference of causal direction. Right: Example density distributions of unknown(red line), known(blue line) causality suggestions and information(orange circles) distribution of unknown suggestions.

(Takashi Isozaki and Masatoshi Funabashi)

\section{P2P Food Lab}

The goal of the P2P Food Lab project is to develop innovative and sustainable solutions for the growing, harvesting, transporting, consumption, and disposal of 
food. We evaluate new technologies that support new modes of crop production, in particular small-scale and micro agriculture. As we are fully aware that technology alone cannot solve the current crises that our society is facing, including the challenges facing agriculture today $[72,74,73,80]$, P2P Food Lab includes a strong social aspect and aims to build alternative solutions using a bottom-up approach that involves all stakeholders, including citizens. The first phase of the P2P Food Lab project is to design an on-line/offline platform that groups the four main pillars - agriculture, communities, technology, and science, - and to leverage the network effect to engage many people and increase the social impact of the platform.

\subsection{P2P Food Lab Starter Kit}

In our first experiment, during Summer 2014, we developed a "Starter Kit" for micro-agriculture that consisted of a small, Internet-connected greenhouse. A sensor box was placed inside the greenhouse that took daily images of the crops and measured the air temperature, air humidity, and sunlight. The sensor box was built using standard off-the-shelf components such as Arduino, Raspberry $\mathrm{Pi}$ and standard webcams. The goal of the connected greenhouse was to create an on-line social network of participants and gardeners, and evaluate the use of sensors for the study of crop growing.
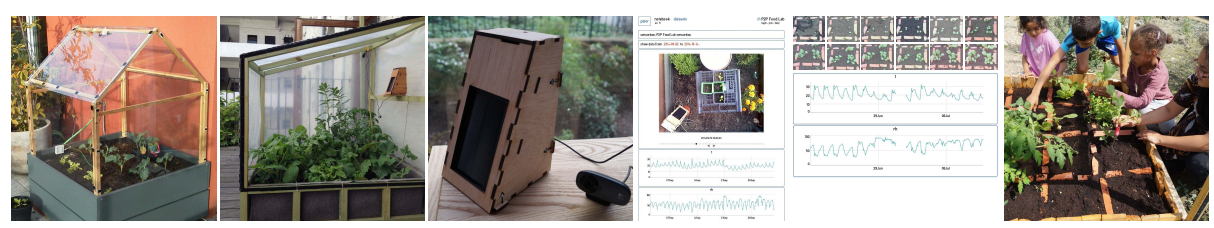

Fig. 3. From left to right: 1) The first P2P Food Lab greenhouse near Paris, 2) Subsequent version of the greenhouse in Brussels, 3) Sensor box with camera, 4) Screenshot from the web site, 5) Time-lapse of the radishes and weather data, 6) Children from participating school near Paris.

\subsection{The CitizenSeeds Experiment}

The Starter Kit still represented an entry point that was too steep to engage many people. We also found that we needed to give participants clearer guidelines in order to obtain reusable data. Consequently, we simplified the requirements for participation in Summer 2015. In the new experiment, called CitizenSeeds, participants only needed a camera-equipped mobile phone and a $1 \mathrm{~m}^{2}$ plot of land (raised bed or plain soil). We also defined a fixed collection of seeds to plant and a fixed, shared planting schedule. These two elements greatly help in aligning the participants, comparing the data, and stimulating social interaction. 
To measure the environmental data (sunlight, air temperature, soil humidity) the participants had the option to use the Flower Power device produced by the Parrot company. They also had the possibility to buy soil for their plot to normalise the soil used in the experiment, however few participants chose this option.

Participants are asked to upload photos of their plot and the vegetables once a week. About 80 people registered of which about 30 contribute to the experiment. A single web page displays the states of the plots and the environmental data of the community ${ }^{\ddagger}$.

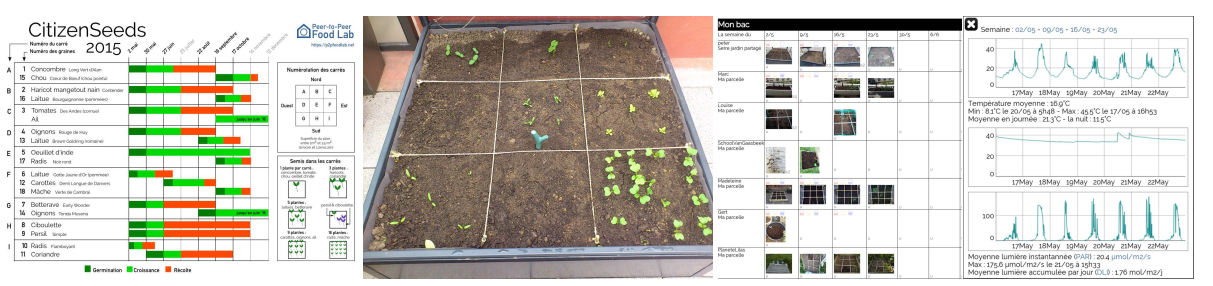

Fig. 4. From left to right: 1) The seeding calendar, 2) A $1.2 \times 1.2 \mathrm{~m}$ plot with seedlings, 3) Matrix of photos uploaded by participants, 4) Visualisation of recorded environmental data.

\subsection{Future developments}

The Citizen Seeds project seems to have the right level of ingredients to evolve into an on-line platform for micro-agriculture. The main long-term developments that we envision are:

- Distributed organisation: Scaling up from tens of participants to thousands of participants will require the introduction of new organisational scaffolding structures [66].

- Citizen Science: Introduce well-defined protocols for planting and measuring in order to perform scientific experiments with the involvement of many amateur gardeners. Topics of interest to be studied include analysing the effects of crop intermixing $[69,71,79,78]$, measuring the evolution of soil biology $[68,67]$, tracing the phenotypical adaptation of varieties to local conditions.

- Increase plot size: Develop similar experiments and data sharing for larger plots and with (semi-)professional participants. The biggest interest is to study alternative farming techniques [77] that have been studied very little by agronomists until now, including synecoculture, permaculture [65,64], and bio-intensive micro-farming [76]. The platform also allows the community explore new technological tools and sensors to monitor and optimise these cropping techniques, using a collaborative approach $[70,75]$.

\footnotetext{
$\mp$ See https://p2pfoodlab.net/CitizenSeeds/experiments/4.html
} 
(Peter Hanappe)

\section{The Sound Beehive Experiment}

\subsection{Overview}

The Sound Beehive Experiment monitors the development of a bee colony on the basis of the sounds it generates, and creates artistic expression mediated by artificial intelligence. For this purpose, we developed a beehive that is equipped with sensors, microphones and cameras. The Sound Beehive is installed in the Urban Bee Laboratory on a rooftop in the Brussels city centre. Data is streamed to central repositories and analyzed using statistical techniques and graphic visualizations.

\subsection{Introduction}

An Ethological Approach Honeybees are bio-indicators. They provide a constant stream of information on the environment in which they forage, via their daily activity, and via the pollen and nectar they harvest. Environmental problems such as the use of pesticides can be detected by monitoring the colonies with audio and video tools and by scanning their daily activity over several years [81]. In nearly all industrialized nations, bee colonies are now threatened. The compromised state of the foraging areas for bees is worrisome. By using bees as bio-indicators and by translating the information into artworks, This project aims to make citizens aware of the increasingly negative effects of our lifestyle and methods of industrial production. AnneMarie Maes is a media artist collaborating with computer scientists and engineers to develop art-science projects. Interested in showing the hidden structures in nature, we try to use innovative technological methods to probe the living world.

\subsection{Methods}

Basic Elements To study the bees in their natural environment, following the footsteps of von Frisch and other ethologists [82], we have built a customized 'sound device'. Microphones inside the beehive enable us to continuously monitor the colony's buzz. Together with outside and inside video monitoring it forms a non-intrusive scanning device for controlling the colony's health and development. We also installed a network of temperature and humidity sensors spread throughout the beehive. The annotated video and audio data are uploaded to our open source video database [83]. All time-stamped sensor data from the lab's weather station, as well as the temperature and humidity data measured inside the beehive, are made public on [84]. 
Instrumentation Our custom-built audio, video and sensor device is integrated in a Warré beehive (Fig.5). It is a sustainable beehive in which the colony develops at its own pace. We started to customize our Warré beehive by putting electret microphones in the top cover and by attaching contact microphones in the frames of the brood box. All microphones are connected to pre-amps stored in the rooftop. They are powered by a battery that is located a few meters away from the hive to avoid the creation of electro-magnetic fields.

For recording the video images, we use Raspberry Pi computers. The Raspberry can be easily integrated in complex installations and is equipped with a series of USB and Ethernet connections to function in a network of devices. We integrated two small high-resolution cameras in our setup; one camera to record the activity on the landing platform and a second infrared camera to registrate the activity inside the brooding box.

The analysis of the images gives us information on the relation of the bees to the environment. A beecounter is integrated in order to determine the in/out flux and detect homing problems related to pesticide contamination. The images also give us information about the pollen supply and the development of the colony related to the activity level of forager bees, fanning bees, dead bees and lazy bees on the landing platform.

Sensing of Bee Activity Related to the Environment A bee colony is very responsive to the biotopes of which it is a part. The production of honey is dependent on the flowers we grow, the plants we like, and the garbage or pollution we produce. The colony is also very sensitive to environmental variables such as outside temperature, rainfall and humidity, the wind and hours of sunshine. We therefore compare the behavior of the bees and the development of the colony with the data from the weather station. In our rooftop field lab, we have installed a Libellium agriculture kit[85], including several environmental sensing devices. E.g., the hours of solar activity, as well as the soil composition, determine the nectar flow of the flowers and their visits by the bees. Nectar secretion increases as pollinators visit the flower.

We set up a database of the pollen contained in the honey of our urban bee colonies and we started to determine the pollen source. By studying the pollen in a sample of honey, it is possible to collect evidence of the geographical location and genus of the plants that the honeybees visited[86]. As such, we start to trace green corridors through the city.

Data Processing In January 2015 we started analyzing the recorded files. We scanned the sound files in terms of their brightness, loudness and noise level. For the analysis of the video files, we made use of motion detection via the frame difference method. The analysis of the sound files is a complex matter. We therefore use techniques of Artificial Intelligence in collaboration with the Brussels Free University. We have recorded large amounts of data in order to investigate whether we can detect patterns. All together these data give us plenty of parameters to combine and to play with, to create models and to compare 
different moments in time and thus to study the behavior of the colony relative to timeline/season and environmental parameters.

\subsection{Visual Expression of the Sound Beehive}

A video shows a graphical rendering of AI analysis of colony behavior combining real audio data with measurements of the microclimate inside the hive: temperature, CO2 and humidity Another video shows 365 days of activity inside a real observation beehive, played back at high speed. The images were recorded with an infrared camera inside the hive and processed using pattern recognition, AI and computer graphics algorithms. These images offer the stunning visual experience of a bee colony in action (Fig.6). To create an immersive sound installation we analyzed the sound files recorded in the hive. The Scaffolded Sound Beehive (Fig.7) is a wooden sculpture, constructed using open source digital fabrication and mounted on scaffolds of 2,5 meters high. Visitors can enter this upscaled model of the Warré beehive and experience an auditory artistic interpretation of hive activity. We processed the recordings (made in the real beehive) using sophisticated pattern recognition algorithms and artificial intelligence analysis software, and edited the sound files by adding swirling electronic sound clusters to sonify the ebb and flow of swarm activity in the hive.

\subsection{Art Exhibition}

The Sound Beehive immersive installation has been shown at the Institute of Evolutionary Biology (IBE) in Barcelona (May-June 2015)[87], and at the AI and the Arts exhibition for the international conference of Artificial Intelligence in Buenos Aires, Argentina (July 2015)[88]. The enormously positive response of viewers shows clearly that the presentation of scientifically inspired art can have a strong impact and raises awareness of important societal issues, and also that art-inspired science can have a fruitful positive effect to push science in new directions. 


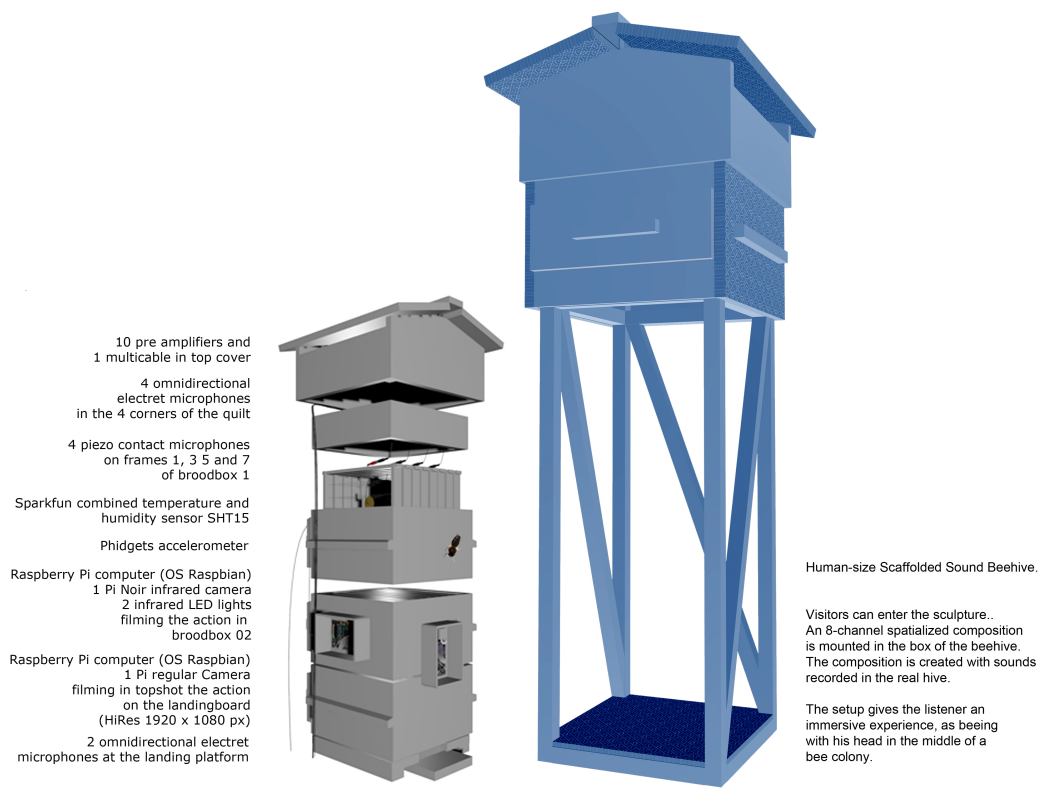

Fig. 5. Left: Diagram of the instrumented Sound Beehive, Right: the Scaffolded Sound Beehive Sculpture

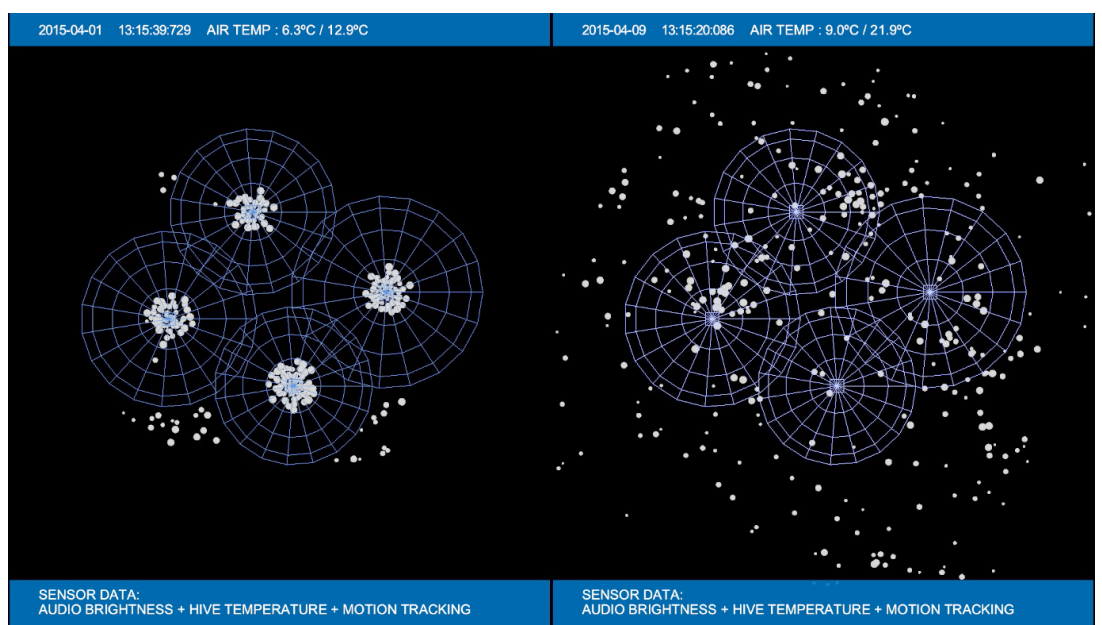

Fig. 6. Analysis of the data collected in the beehive, comparison between 2 days. The data used for visualization are: audio brightness (4 sources), the temperature inside the beehive and the motion tracking on the landing platform. 


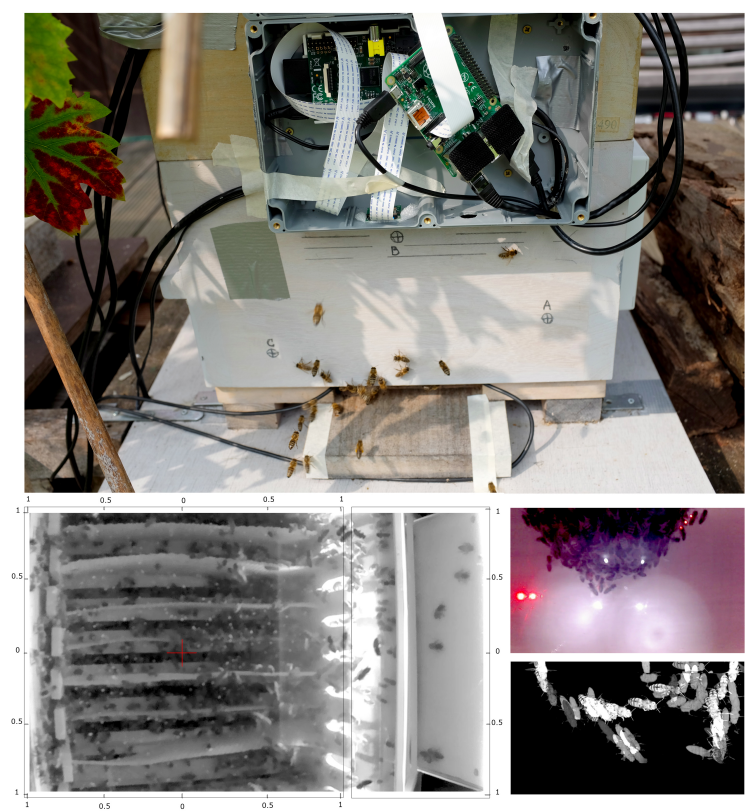

Fig. 7. Top: streaming activity on the landing platform. Bottom: video-analysis of the activity inside the beehive.

\section{Open Systems Simulation}

\subsection{Motivation}

We as a modern society are facing many urgent yet unsolved problems, including the possible global shortage of natural resources and food, environmental pollution, economic instability, poverty, crisis of medical and health care systems, social insecurity, computer and network fragility, and so on. All of these are problems of open systems, which is literally a system that is open to the outer world and shows temporal development as interactions with the outer world progress[89]. As a consequence, we can neither have full control over the systems nor restart from the beginning to let them reproduce identical behaviors. Science has had difficulties in handling these kinds of problems because its methods rely on validation or falsification of hypotheses by observing reproducible instances. However, if simulation virtually reproduces an one-time-only-problem, the boundary of applicable range of science can be pushed far beyond. Based on the above insight, an ultimate goal of the open systems simulation is to develop a framework and methods of simulation that can handle open systems problems in a constructive and an operational way. 


\subsection{Practice}

Epidemics is an important factor of social-ecological systems that threatens productivity and sustainability. As a specific instance, we have been developing an integrated simulation of infectious disease, especially targeted for influenza[90] [91]. In order to understand the essential aspects of influenza epidemiology, it is not enough to simply look into a particular part such as the micro mechanisms and processes of infection separately in a closed manner. We need to simultaneously take into account surrounding yet further-reaching factors, such as the structure and dynamics of human society, the population dynamics of humans, ecosystems (including those of other species), seasonal conditions, geographical constraints, and so on in order to take an integrated and holistic view. As a first step of our endeavor, we have built a bi-layered model which interconnects macro simulation of epidemic circulation among hosts and micro simulation of viral evolution driven by immunological interaction among hosts and viruses. In the model, we showed possible mechanisms that generate the limited diversity of viruses, which is one of the fundamental yet unexplained temporal behaviors observed in the evolution of real influenza.

(Takahiro Sasaki)

\section{One-Health Food Lab}

Under the slogan of "One World, One Health", the Wildlife Conservation Society convened public health experts from around the world to adopt the Manhattan Principles in 2004. The first principle is: "Recognize the essential link between human, domestic animal and wildlife health and the threat disease poses to people, their food supplies and economies, and the biodiversity essential to maintaining the healthy environments and functioning ecosystems we all require." It exemplifies the interdisciplinary movement toward solving the world's complex, interlocking problems, rather than simply taking reactive countermeasures against zoonotic diseases [92]. In One-Health Food Lab, we scientifically examine foods and medicinal herbs, which were produced in different growth conditions and placed in the market, to evaluate their quality and safety to the health of human and other creatures sharing the earth.

\subsection{Activity in 2014}

In 2014, we studied functions, compositions and tastes of common vegetables in relation with their farming methods: Conventional $(\mathrm{C})$, Organic $(\mathrm{O})$ and Nat$\mathrm{ural}^{\S}(\mathrm{N})$. In one study on cabbage using a smart taste-sensing system for five different tastes (sweetness, saltiness, sourness, umami and bitterness), bitterness was found to be the one that significantly differentiated N-cabbage from the others and also the most lasting one among the tastes [93]. In another study through

\footnotetext{
$\S$ Synecoculture products in section 2 .
} 
absorption spectroscopy and metabolome analysis, the UV-absorption level and the phytochemical content were both detected to hold the order $\mathrm{N}_{i} \mathrm{O}_{\dot{ }} \mathrm{C}$ in cabbage or $\mathrm{C}_{\dot{ }} \mathrm{O}_{\dot{ }} \mathrm{N}$ in carrots [94]. In addition, antibiotics were found in O-products; pesticides, carcinogens and synthetic drugs were detected independently of the farming method. Through these studies, physiological differences of plants related with their growth environment and their effects on human health as foods and drugs have been partly elucidated.

(Kaoru Yoshida)

\section{Conclusion}

With the perspective of open complex systems, 6 projects have begun to collaborate in e-laboratory that independently interact and tackle the urging problems of food production in various aspects of social-ecological systems. The founding philosophy and initial steps of exploration are demonstrated as a progress report. Without any top-down restriction of methodology and expression other than open complex systems, our projects are in open collaboration inside and outside of the e-laboratory, expecting bottom-up convergence of new ideas that could be supported by plural independent scientific paths.

We also expect that with this form of collaboration, new effective methodologies to treat open complex systems might be elaborated, not necessary constrained in food production but applicable to a wide range of open systems problems. When combined with interactive technologies and cloud computation, data analytics and simulation are traditional yet prominent domains to trigger such change in scientific methodologies.

The design of agriculture varies according to the local climate condition, selection of culture species, available resources, preference of consumers, health effect, disease risks, environmental preservation effort, economical state, community dynamics, means of distribution, etc, which are assigned parallelly in each project. We require an integrated approach to widen the choice of possible strategies in order to develop sustainable food production in an ever-changing environment. At the same time, fundamental question such as ecosystems function and health effect of food should maintain scientific objectivity without catering to a specific social activity. From each part to the whole, subsystems related to food production should be redefined while operating as open complex systems, intriguing effective social-ecological change with a scientific support.

This e-laboratory is a challenge that brings us back to the origin of agriculture and question de novo the design of food production ranging from urban gardening to natural state. The methodology and expression vary among projects, though we commonly share the mutual principle of challenge: Human activities from industrial production to citizen initiative should bring positive impacts on nature by augmenting the ecological state, and human society in return benefits from its ecosystem services. Human augmentation of ecosystems, or ecosystems leveraging, that exceeds the conventional reach of agriculture. 
A possible outcome from this challenge is the derivation of a protocol that can infer and continuously ameliorate a suitable and sustainable food production system in a wide range of social-ecological condition. This protocol is not a mere ensemble of past data in various environment, but a trial-and-error tutorial that describes how to yield a concrete design of agricultural system in a given transient condition. This corresponds to a meta-algorithm that constantly integrates new data and provides wider choice of exploration in the practice of agriculture. The protocol should be extensively applicable in any arable and social condition, including future climate change. The tailoring of site-specific management system is expected to bring self-sufficient practice for the natural source management in highly variable and diverse farm conditions typical of resource-poor farmers in developing world, which is estimated to be about 1.4 billion people [95].

The databases, tools, and tutorials developed in each project will gradually be available in public including the CS-DC interfaces.

\section{Acknowledgement}

We acknowledge Hidemori Yazaki, Kousaku Ohta, Tatsuya Kawaoka, Kazuhiro Takimoto, and Shuntaro Aotake who worked as research assistant in the sections 2 and 3, Kana Maruyama and Tatsuya Hiroishi in the section 3.

\section{References}

1. Carter, V.G., Dale, T., Topsoil and Civilization, University of Oklahoma Press(1975)

2. Montgomery, D.R., Dirt: The Erosion of Civilizations, University of California Press (2012)

3. Barnosky, A.D. et al., Approaching a state shift in Earth's biosphere, Nature, Vol 486, pp 52-58, 7(2012)

4. International assessment of agricultural knowledge, science and technology for development (IAASTD) : synthesis report with executive summary : a synthesis of the global and sub-global IAASTD reports(2009). http://www . unep.org/dewa/agassessment/reports/IAASTD/EN/AgricultureataCrossroads_ SynthesisReport (English).pdf

5. World development report, Agriculture for Development(2008). http: //siteresources . worldbank . org/INTWDRS/Resources/477365-1327599046334/ 8394679-1327614067045/WDROver2008-ENG.pdf

6. World Economic Forum, Realizing a New Vision for Agriculture: A roadmap for stakeholders(2010). http://www3. weforum.org/docs/WEF_IP_NVA_Roadmap_ Report.pdf

7. World Economic Forum, Achieving the New Vision for Agriculture: New Models for Action(2013). http://www3.weforum.org/docs/IP/2013/NVA/WEF_IP_NVA_ New_Models_for_Action_report.pdf

8. United Nations Environment Programme (UNEP), The environmental food crisis The environment's role in averting future food crises(2009). http://www . unep.org/ pdf/FoodCrisis_lores.pdf 
9. Avoiding Future Famines: Strengthening the Ecological Foundation of Food Security through Sustainable Food Systems. United Nations Environment Programme (UNEP), Nairobi, Kenya(2012). http://www.unep.org/publications/ ebooks/avoidingfamines/portals/19/UNEP_Food_Security_Report.pdf

10. , Investing in smallholder agriculture for food security. A report by the High Level Panel of Experts on Food Security and Nutrition of the Committee on World Food Security, Rome(2013). http://www.fao.org/fileadmin/user_upload/hlpe/ hlpe_documents/HLPE_Reports/HLPE-Report-6_Investing_in_smallholder_ agriculture.pdf

11. Rosenqvist, A. A review of remote sensing technology in support of the Kyoto Protocol, Environmental Science \& Policy 6 (2003) 441-455

12. Smith, L.C., Satellite Remote Sensing of River Inundation Area, Stage, and Discharge: a Review, Hydrological Processes, Vol.11, 1427-1439(1997).

13. Thop, K.R., Tian, L.F., A Review on Remote Sensing of Weeds in Agriculture, Precision Agriculture, 5, 477-508(2004).

14. McVigar, T.R., Jupp, D.L.B., The Current and Potential Operational Uses of Remote Sensing to Aid Decisions on Drought Exceptional Circumstances in Australia a Review, Agricultural Systems, Vol 57, No 3, pp. 399-468(1998).

15. Green, E. P. et al., A Review of Remote Sensing for the Assessment and Management of Tropical Coastal Resources, Coastal Management, 24:1-40(1996).

16. Dorigo, W.A. et al., A review on reflective remote sensing and data assimilation techniques for enhanced agroecosystem modeling, International Journal of Applied Earth Observation and Geoinformation,Volume 9, Issue 2, May 2007, Pages 165-193 (2007)

17. Homgren, P., Thuresson, T., Satellite Remote Sensing for Forestry Planning, Scand. J. For. Res. 13:90-110 (1998).

18. Lynch, J., Choose satellites to monitor deforestation, Nature, Vol 496, 293-294 (2013).

19. Tucker, C.J., A critical review of remote sensing and other methods for nondestructive estimation of standing crop biomass, Grass and Forage Science, Vol $35,177-182(1980)$.

20. Mader, P. et al., Soil Fertility and Biodiversity in Organic Farming, Science, Vol 296, 1694-1697 (2002)

21. Burlingame, B. (Ed), Proceedings of the International Scientific Symposium BIODIVERSITY AND SUSTAINABLE DIETS UNITED AGAINST HUNGER, 3-5 November 2010, FAO Headquarters, Rome (2010) http://www.fao.org/docrep/ 016/i3004e/i3004e.pdf

22. Walker, S., Wilson, J. B., Steel, J.B., Rapson, G.L., Smith, B., King, W.M.G., Cottam, Y. H., Properties of Ecotones: Evidence From Five Ecotones Objectively Determined From A Coastal Vegetation Gradient. Journal of Vegetation Science 14(4):579-590 (2003).

23. Pool, R., Ecologists Flirt with Chaos,Science, New Series, Vol. 243, No. 4889, Jan. 20, pp. 310-313 (1989).

24. Cushing, J.M. et al., Chaos in Ecology, Academic Press, (2002)

25. Millennium Ecosystem Assessment, 2005. Ecosystems and Human Well-being: Biodiversity Synthesis. World Resources Institute, Washington, DC(2005). http: //www . unep.org/maweb/documents/document.354.aspx.pdf

26. Global Biodiversity Information Facility, http://data.gbif.org/welcome.htm; jsessionid=F6C5F068ACF892631397FBB91CBE91D8

27. Japan Node of Global Biodiversity Information Facility, http://www .gbif .jp/v2/ 
28. Japan Integrated Biodiversity Information System, http://www.biodic.go.jp/ english/J-IBIS.html

29. EU- project KNEU-Developing a Knowledge Network for EUropean expertise on biodiversity and ecosystem services to inform policy making economic sectors, BiodiveristyKnowledge, http://www.biodiversityknowledge.eu/project

30. Tree of Life web project, http://www.tolweb.org/tree/

31. Encyclopedia of Life, http://eol.org/

32. Global Biodiversity model for policy support, http://www.globio.info/home

33. Groombridge, B., Jenkins, M.D., World Atlas of Biodiversity: Earth's Living Resources in the 21st Century, University of California Press (2002).

34. Kuhnlein, H.V. et al.(Ed), Indigenous Peoples' Food systems \& well-being, Food and Agriculture Organization of the United Nations, Center for Indigenous Peoples' Nutrition and Environment, Rome (2013) http://www.fao.org/docrep/018/ i3144e/i3144e00.htm

35. WHO Technical Report Series 916, Diet, Nutrition and The Prevention of Chronic Disease Geneva (2003)

36. Harvard School of Public Health, The Global Burden of Non-communicable Diseases, A Report by the World Economic Forum and the Harvard School of Public Health (2011)

37. Goodchild,M.F., Citizens as sensors: the world of volunteered geography, GeoJoumal (2007) 69:211-221 (2007)

38. Sheppard, S.R.J., Cizek, P., The ethics of Google Earth Crossing thresholds from spatial data to landscape visualization, Journal of Environmental Management, 90, 2102-2117 (2009)

39. e-laboratory website, \{http://www.elab-ose4el.net/\}

40. Graham, L.E., Origin of Land Plants, Wiley (1993).

41. Putman, R. J., Wratten, S. D., Principles of Ecology, University of California Press (1984).

42. Hector A. et al., Plant Diversity and Productivity Experiments in European Grasslands, Science, Vol 286, 1123-1127 (1999).

43. Aiba, S. et al., Dynamics, productivity and species richness of tropical rainforests along elevational and edaphic gradients on Mount Kinabalu, Borneo, Ecol Res, 20: 279-286 (2005).

44. Glover, D. et al., Increased Food and Ecosystem Security via Perennial Grains, Science, Vol.328 no.5986 pp. 1638-1639 (2010).

45. Glover, D. et al., Plant Perennials to Save Africa's Soils, Nature, Vol 489, 359-361 (2010).

46. Jackson W., Natural systems agriculture: a truly radical alternative, Agriculture, Ecosystems and Environment, 88, 111-117 (2002).

47. Huggins,D.R. et al., No-Till: the Quiet Revolution, Scientific American, July, pp.70$77(2008)$

48. Fukuoka, M., The One-Straw Revolution: An Introduction to Natural Farming, Rodale Press (1978).

49. Funabashi, M., IT-Mediated Development of Sustainable Agriculture Systems Toward a Data-Driven Citizen Science, Journal of Information Technology and Application in Education, 2(4), 179-182 (2013).

50. FUNABASHI, M., Fondation de la Synécoculture: Vers une agriculture de synthèse écologique et rentable, Actes du colloque Transversalités de l'Agriculture Biologique (2011). English translation available at: https://www.sonycsl.co.jp/ publications/result/?langmode=jp\&bykeyword=funabashi 
51. Newbold, T., et al., Global Effects of Land Use on Local Terrestrial Biodiversity, Nature, 2 apr, vol 520, pp.45-50 (2015)

52. Hashimoto, S., Nakamura, S., Saito, O., Kohsaka, R., Kohriki, C., Tanaka, R., Measuring ecosystem services of social-ecological production landscapes of Noto: toward the economics of Satoyama, Proceedings of International Conference, Sustainable Management including the use of Traditional Knowledge in Satoyama and Other SELPS, pp.17-26 (2014)

53. Kottek, M., Grieser, J., Beck, C., Rudolf, B., Rubel, F., World Map of the KöppenGeiger climate classification updated. Meteorol. Z., 15, 259-263 (2006).

54. Holdridge, L.R. Determination of world plant formations from simple climatic data. Science, 105, 367-368 (1947).

55. Verbitskii, V.B., Verbitskaya, T. I., Ecological Optimum and Effect of Delayed Action of a Factor, Doklady Biological Sciences, Vol. 416, pp. 386-388 (2007)

56. Lévi-Strauss, C. La Pensée Sauvage, Pocket (1990)

57. Isozaki, T., Ueno, M., Minimum Free Energy Principle for Constraint-Based Learning Bayesian Networks, Proc. of ECMLPKDD 2009, Part1, LNAI5781, pp. 612-627 (2009).

58. Isozaki, T., Combining Stage Algorithm for Discovering Causal Models, Proc. of UAI Workshop on Causal Structure Learning (2012)

59. Tokoro, M.: What is Open Systems Science? In: Tokoro, M. (Ed.) Open Systems Science: From Understanding Principles to Solving Problems (The Future of Learning). IOS Press (2010)

60. Tokoro, M.: A New Method for New Challenges. Scientific American, Innovation Special Issue, pp. 64-66 (2015)

61. Reichenbach, H.: The Direction of Time. Dover Publications (1956)

62. Pearl, J: Causality, Models, Reasoning, and Inference. Cambridge University Press (2000)

63. Isozaki, T.: A Robust Causal Discovery Algorithm against Faithfulness Violation. Trans. of the Jpn Soc. for Artificial Intelligence. 29(1), 137-147 (2014)

64. Bell, G. (2005). The Permaculture Way, Chelsea Green Publishing.

65. Mollison, B. and Holmgren, D. (1978) Permaculture One: A Perennial Agriculture for Human Settlements, Trasworld Publishers, 1978. ISBN 978-0-938240-00-6.

66. Lane D., Maxfield R., Read D., van der Leeuw S. (2009). From Population to Organised Thinking. In Lane D., van der Leeuw S., Pumain D., West G.(Eds) Complexity Perspectives in Innovation and Social Change, Springer Verlag.

67. Bärlocher F. (2005). Leaf Mass Loss Estimated by Litter Bag Technique. In: Methods to Study Litter Decomposition. pp. 37-42. Springer Netherlands.

68. Abbott L.K. and Murphy D.V. (2003). Soil Biological Fertility, A Key to Sustainable Land Use in Agriculture. Springer.

69. Bedoussac L., Justes E., Journet E.-P, Hauggaard-Nielsen H., Naudin C., CorreHellou G., Prieur L., Jensen E.S. (2014). Intercropping 2014. An application of ecological principles to improve nitrogen use efficiency in organic farming systems. In: Organic farming, prototype for sustainable agricultures, Bellon S. and Penvern S. (eds.) Springer.

70. Campbell, D. C., Carlisle-Cummins, I., and Feenstra, G. (2013). Community food systems: Strengthening the research-to-practice continuum. Journal of Agriculture, Food Systems, and Community Development, 3(3), 121138. http://dx.doi.org/10.5304/jafscd.2013.033.008

71. Corre-Hellou G., Dibet A., Hauggaard-Nielsen H., Crozat Y., Gooding M., Ambus P., Dahlmann C., von Fragstein P., Pristeri A., Monti M., Jensen E.S. (2011). The 
competitive ability of pea barley intercrops against weeds and the interactions with crop productivity and soil N availability. Field Crops Research 122, 264272.

72. De Schutter, O. (2014). Report of the Special Rapporteur on the right to food, United Nations General Assembly, 2014

73. EEA (2015). The European environment state and outlook 2015: synthesis report, European Environment Agency (EEA), Copenhagen, 2015.

74. FAO (2014). The State of Food and Agriculture, Food and Agriculture Organization of the United Nations, Rome. http://www.fao.org/3/a-i4040e.pdf

75. Introne, J., Laubacher, R., Olson, G., and Thomas M. (2014). Solving Wicked Social Problems with Socio-computational Systems, Kunstliche Intelligenz, February 2013.

76. Jeavons, J. (2012) How to Grow More Vegetables (and Fruits, Nuts, Berries, Grains, and Other Crops) Than You Ever Thought Possible on Less Land Than You Can Imagine, Eighth Edition, Ten Speed Press, 2012.

77. Kremen, C., Iles, A. and Bacon, C. (2012). Diversified farming systems: an agroecological, systems-based alternative to modern industrial agriculture. Ecology and Society 17(4): 44 .

78. Loreau M. and Hector A. (2001). Partitioning selection and complementarity in biodiversity experiments. Nature 412: 72-76.

79. Malézieux E., Crozat Y., Dupraz C., Laurans M., Makowski D., Ozier-Lafontaine H., Rapidel B., de Tourdonnet S., Valantin-Morison, M. (2008). Mixing plant species in cropping systems: concepts, tools and models. A review. Agronomy for Sustainable Development, 29, 4362.

80. SOER (2010). The State of Soil in Europe, A contribution of the JRC to the European Environment Agencys Environment State and Outlook Report, European Environment Agency.

81. Michels, M. A Beehive Monitoring System Incorporating Optical Flow as a Source of Information, Masters thesis. Freie Universität Berlin (2011).

82. Von Frisch, K., The Dancing Bees: An Account of the Life and Senses of the Honey Bee, Harvest Books New York (1953)

83. The Bee Laboratory open source video database, http://pandora.okno.be

84. The Bee Laboratory open sensor data, http://opensensordata.net

85. Libellium agriculture kit, http://www.libelium.com/products/waspmote/

86. The Bee Laboratory pollen database, http://urbanbeelab.okno.be/doku.php? id=pollen_database

87. The Sound Beehive installation at the Institute of Evolutionary Biology (IBE) in Barcelona (May-June 2015), http:// annemariemaes.net/presentations/bee-laboratory-presentations-2/ bee-monitoring-devices-and-curious-observations/

88. The Sound Beehive installation at the AI and the Arts exhibition for the international conference of Artificial Intelligence in Buenos Aires, Argentina (July 2015), http://annemariemaes.net/presentations/bee-laboratory-presentations-2/ artes-ijcai/

89. Tokoro, M. ed., Open Systems Science From Understanding Principles to Solving Problems, IOS Press, jan. (2010)

90. Sasaki, T. Hierarchical Multi-Agent-Based Modelfor Simulating the Prevalence and Evolution of Influenza Virus, Spring Simulation Multi-Conference, pp.62-69, apr. (2013)

91. Sasaki, T. Simulating Limited Diversity in Evolution of Influenza, ECAL 2013: 12th European Conference on Artificial Life, pp.470-471, sep. (2013) 
92. GRF One Health Summit http://onehealth.grforum.org/about/ about-one-health/

93. Yoshida, K., Shimizu-Yoshida, Y., Funabashi, M. Functional and compositional characteristics of conventionally, organically and naturally grown cabbage and carrots. 4th International Conference on Food Studies, October 20-21, Prato, Italy (2014).

94. Yoshida, K., Funabashi, M. Taste analysis on conventionally, organically and naturally grown cabbage. 1st IMEKOFOODS, October 12-15, Rome, Italy (2014).

95. Altieri, M. A. Agroecology: the science of natural resource management for poor farmers in marginal environments, Agriculture, Ecosystems and Environment 1971 $1-24(2002)$ 